\title{
Duloxetine in the treatment of major depressive disorder: an open-label study
}

\author{
James I Hudson' ${ }^{1}$ David G Perahia ${ }^{2,3}$, Inmaculada Gilaberte ${ }^{2}$, Fujun Wang2, \\ John G Watkin ${ }^{2}$ and Michael J Detke*1,2,4
}

Address: ${ }^{1}$ McLean Hospital, Belmont, MA and Department of Psychiatry, Harvard Medical School, Boston, MA, USA, ${ }^{2}$ Lilly Research Laboratories, Eli Lilly and Company, Indianapolis, IN, USA, ${ }^{3}$ The Gordon Hospital, London, UK and ${ }^{4}$ Department of Psychiatry, Indiana University School of Medicine, Indianapolis, IN, USA

Email: James I Hudson - jhudson@mclean.harvard.edu; David G Perahia - d.perahia@lilly.com; Inmaculada Gilaberte - gilaberte@lilly.com; Fujun Wang - wangfu@lilly.com; John G Watkin - watkinj@saic.com; Michael J Detke* - mdetke@lilly.com

* Corresponding author

Published: 28 August 2007

BMC Psychiatry 2007, 7:43 doi:10.1/86/147|-244X-7-43
Received: 28 August 2006

Accepted: 28 August 2007

This article is available from: http://www.biomedcentral.com/I47I-244X/7/43

(c) 2007 Hudson et al; licensee BioMed Central Ltd.

This is an Open Access article distributed under the terms of the Creative Commons Attribution License (http://creativecommons.org/licenses/by/2.0), which permits unrestricted use, distribution, and reproduction in any medium, provided the original work is properly cited.

\begin{abstract}
Background: Major depressive disorder (MDD) is a chronic and highly disabling condition. Existing pharmacotherapies produce full remission in only $30 \%$ to $40 \%$ of treated patients. Antidepressants exhibiting dual reuptake inhibition of both serotonin (5-HT) and norepinephrine (NE) may achieve higher rates of remission compared with those acting upon a single neurotransmitter. In this study, the safety and efficacy of duloxetine, a potent dual reuptake inhibitor of 5-HT and NE, were examined.

Methods: Patients ( $\mathrm{N}=533)$ meeting DSM-IV criteria for MDD received open-label duloxetine $(60 \mathrm{mg}$ once a day [QD]) for 12 weeks during the initial phase of a relapse prevention trial. Patients were required to have a 17-item Hamilton Rating Scale for Depression $\left(\mathrm{HAMD}_{17}\right)$ total score $\geq 18$ and a Clinical Global Impression of Severity (CGI-S) score $\geq 4$ at baseline. Efficacy measures included the HAMD 17 total score, HAMD $_{17}$ subscales, the CGI-S, the Patient Global Impression of Improvement (PGI-I) scale, Visual Analog Scales (VAS) for pain, and the Symptom Questionnaire, Somatic Subscale (SQ-SS). Quality of life was assessed using the Sheehan Disability Scale (SDS) and the Quality of Life in Depression Scale (QLDS). Safety was evaluated by recording spontaneously-reported treatment-emergent adverse events, changes in vital signs and laboratory analytes, and the Patient Global Impression of Sexual Function (PGI-SF) scale.

Results: The rate of discontinuation due to adverse events was II.3\%. Treatment-emergent adverse events reported by $\geq 10 \%$ duloxetine-treated patients were nausea, headache, dry mouth, somnolence, insomnia, and dizziness. Following 12 weeks of open-label duloxetine therapy, significant improvements were observed in all assessed efficacy and quality of life measures. In assessments of depression severity $\left(\mathrm{HAMD}_{17}, \mathrm{CGI}-\mathrm{S}\right)$ the magnitude of symptom improvement continued to increase at each study visit, while for painful physical symptoms the onset of improvement was rapid and reached a maximum after 2 to 3 weeks of treatment.
\end{abstract}

Conclusion: In this open-label phase of a relapse prevention study, duloxetine (60 mg QD) was shown to be safe and effective in the treatment of MDD.

Trial registration: NCT00036309. 


\section{Background}

Major depressive disorder (MDD) represents one of the most serious challenges faced by healthcare providers throughout the world, affecting some 18 million people in the United States and 340 million people globally [1]. The negative impact of MDD upon patient well-being and functioning is comparable to that of major chronic medical conditions such as diabetes, hypertension, coronary artery disease, and arthritis [2]. Given the enormous impact of depression upon both the individual patient and the healthcare system as a whole, the need for effective treatment is clear.

Antidepressant medications, in particular the selective serotonin reuptake inhibitors (SSRIs), currently represent the first line of treatment for MDD. SSRIs attained clinical acceptance over tricyclic antidepressants (TCAs) in part due to their improved tolerability profile, including lower rates of anticholinergic events, orthostatic hypotension, sedation, and lower toxicity in overdose $[3,4]$. However, SSRIs have not demonstrated superior efficacy when compared with TCAs [5], and up to half of all depressed patients fail to respond to SSRI therapy [6]. Thus, the need for alternative safe and effective treatments for MDD is clear.

The antidepressant duloxetine is a potent dual reuptake inhibitor of serotonin (5-HT) and norepinephrine (NE) [7], but lacks significant affinity for muscarinic, histaminergic, $\alpha$-adrenergic, dopaminergic, serotonergic, and opioid receptors [8]. Previous double-blind, placebocontrolled studies have established the safety and efficacy of duloxetine in the treatment of MDD [9-14]. For licensing purposes, the European Committee for Proprietary Medicinal Products (CPMP) requires that an antidepressant's short-term effect be maintained for a longer duration. For this reason, a randomized withdrawal study, also called a relapse prevention study, was considered the best design. The study included an initial 12-week, open-label treatment phase followed by a 26-week, double-blind, randomized withdrawal phase. The primary results of the relapse prevention study have been published elsewhere [15]. Here we present results from the initial open-label acute phase of a relapse prevention study, in which a cohort of over 500 patients received duloxetine $(60 \mathrm{mg}$ once-daily) for 12 weeks.

\section{Methods}

\section{Study design}

This was an open-label study conducted at 29 sites in the United States, France, Italy and Spain. Patients meeting entry criteria received duloxetine $60 \mathrm{mg}$ once-daily for 12 weeks. Study visits were scheduled after 1, 2, 4, 7, 10 and 12 weeks of treatment. Study drug consisted of 2 capsules ( $30 \mathrm{mg}$ of duloxetine in each capsule) taken once-daily. If necessary due to tolerability, the dose could be reduced to 1 capsule (duloxetine $30 \mathrm{mg} / \mathrm{d}$ ) at any point during the first 4 weeks of treatment. Patients had to return to 2 capsules once-daily after Week 4 or they were discontinued from the study.

Concomitant medications with primarily central nervous system activity were not allowed, with the exception of benzodiazepines (e.g. lorazepam, diazepam, chlordiazepoxide) and certain hypnotics (chloral hydrate) for a maximum of 6 total days (intermittent or consecutive) during the 12-week period. Use of non-prescription, overthe-counter pain medications (e.g. paracetamol, acetaminophen, ibuprofen) was allowed. Narcotic use was allowed only upon approval by a study physician. Use of certain prescription medications such as ACE inhibitors, antiarrhythmics, or beta-blockers was permitted provided the patient had been on a stable dose for a minimum of 3 months prior to study enrollment.

In accordance with the principles of the Declaration of Helsinki, all patients gave informed consent prior to administration of any study drug or study procedures. The study protocol was approved by both central and local ethical review boards (ERBs) in the 4 countries in which the study was conducted. The participating ERBs included the following: Schulmann and Associates Institutional Review Board (16 sites), Hospital Tarnier Paris-Cochin (4 sites), Policlinico Universitario Udine, Azienda Ospedaliera S. Giovanni Battista, Universita' Di Parma Comitato Etico, Hospital General Yague, Hospital Clinico De Salamanca, Hospital Universitario Nuestra Senora De Valme, Institut Munincipal Assistencia Sanitaria, Hospital General De Vic, and McLean Hospital.

\section{Selection of patients}

All patients met diagnostic criteria for MDD as defined in the Diagnostic and Statistical Manual of Mental Disorders, $4^{\text {th }}$ Edition (DSM-IV) [16]. The diagnosis of MDD was confirmed by the Mini International Neuropsychiatric Interview (MINI) [17]. Baseline disease severity was defined by patients' scores on the 17-item Hamilton Rating Scale for Depression $\left(\mathrm{HAMD}_{17}\right)[18]$, and the Clinical Global Impression of Severity (CGI-S) scale [19]. To be eligible for the study, patients were required to have a $\mathrm{HAMD}_{17}$ total score $\geq 18$ and a CGI-S score $\geq 4$ at two consecutive screening visits.

Study participants were adult outpatients at least 18 years of age, and were recruited from several sources including psychiatric health care centers and TV/radio/print advertisements. Patients were excluded for the following reasons: a current and primary Axis I disorder other than MDD, including but not limited to dysthymia; the presence of an Axis II disorder that could interfere with com- 
pliance with the study protocol; any previous diagnosis of bipolar disorder, schizophrenia, or other psychotic disorders; any anxiety disorder as a primary diagnosis within the past year; serious suicidal risk; lack of response of the current depressive episode to two or more adequate courses of antidepressant therapy at a clinically appropriate dose for a minimum of 4 weeks, or treatment resistant depression; serious medical illness (including any cardiovascular, hepatic, respiratory, hematologic, endocrinologic, renal, or neurologic disease, or clinically significant laboratory abnormality); initiating or stopping psychotherapy within six weeks prior to enrollment; a DSM-IVdefined history of substance abuse or dependence within the past year; a positive urine drug screen for any substance of abuse.

\section{Safety assessments}

Safety measures recorded at every visit included spontaneously reported treatment-emergent adverse events, supine blood pressure (BP), and heart rate (HR). Elevated blood pressure was defined as supine systolic $\mathrm{BP} \geq 140 \mathrm{~mm} \mathrm{Hg}$ and at least $10 \mathrm{~mm} \mathrm{Hg}$ greater than baseline, or supine diastolic $\mathrm{BP} \geq 90 \mathrm{~mm} \mathrm{Hg}$ and at least $10 \mathrm{~mm} \mathrm{Hg}$ greater than baseline. These definitions for elevated blood pressure were based on diagnostic criteria from the Joint National Committee (JNC) on prevention, detection, evaluation, and treatment of high blood pressure [20]. A patient was considered to have a sustained elevation in BP if criteria for elevated systolic or diastolic BP were met at 3 consecutive visits. Potentially clinically significant (PCS) high BP values were defined as: systolic BP $\geq 180$ $\mathrm{mm} \mathrm{Hg}$ and an increase $\geq 20 \mathrm{~mm} \mathrm{Hg}$ from baseline, or diastolic BP $\geq 105 \mathrm{~mm} \mathrm{Hg}$ and an increase $\geq 15 \mathrm{~mm} \mathrm{Hg}$ from baseline. A treatment-emergent elevated HR was defined as a value $\geq 100 \mathrm{bpm}$ with an increase $\geq 10 \mathrm{bpm}$ from baseline, while a PCS elevated HR was defined as $\geq 120 \mathrm{bpm}$ and an increase $\geq 15 \mathrm{bpm}$ from baseline. Criteria used for PCS values for blood pressure and heart rate were developed for previous duloxetine registration studies in conjunction with the FDA's Division of Neuropharmacological Drug Products (DNDP). A PCS value for Fridericia's correction of the QT interval (QTcF) was defined as any postbaseline value $\geq 450 \mathrm{msec}$ for males or $\geq 470$ msec for females with an increase in QTcF of $\geq 30$ msec from baseline. Blood for hematology was collected at baseline and at the last patient visit (Week 12). Blood for chemistry laboratories was collected at baseline and at Weeks 4 and 12. Normal values for laboratory analytes were based on reference ranges provided by Covance Laboratories, Inc (Princeton, NJ). PCS weight changes were defined as an increase or decrease of $\geq 7 \%$ from baseline body weight.

Changes in sexual functioning were assessed by means of the self-rated Patient Global Impression of Sexual Func- tion (PGI-SF) scale [21], which was collected at baseline and at the last study visit. The PGI-SF is a 4-question instrument that assesses: (i) sexual interest/desire, (ii) erection (for men) or vaginal lubrication (for women), (iii) ability to achieve orgasm, and (iv) an overall rating of sexual function. Each question was rated on a 5-point scale ranging from 1 (no impairment) to 5 (severely impaired).

\section{Efficacy measures}

Efficacy measures included the $\mathrm{HAMD}_{17}$ total score; $\mathrm{HAMD}_{17}$ subscales, including anxiety/somatization (sum of Items 10,11,12,13,15, and 17), retardation (sum of Items 1, 7, 8, and 14), sleep (sum of Items 4, 5, and 6), core (sum of Items 1, 2, 3, 7, and 8), and Maier (sum of Items 1, 2, 7, 8, 9, and 10); the CGI-S; the Patient Global Impression of Improvement (PGI-I) scale [19]; Visual Analog Scales (VAS) for pain [22] (six questions regarding the experience of overall pain, headache, back pain, shoulder pain, pain interference with daily activities, and proportion of the day with pain); the Symptom Questionnaire, Somatic Subscale (SQ-SS) [23]; and the pain subscale of the SQ-SS (sum of Items 5 (no pains anywhere), 8 (tight head or neck), 10 (feeling of pressure in head or body), 12 (no aches anywhere), 16 (pressure on head), 19 (muscle pains), 21 (headaches), and 23 (head pains)). Health outcomes were assessed using the Quality of Life in Depression Scale (QLDS) [24] and the Sheehan Disability Scale (SDS) [25].

\section{Statistical methods}

Safety analyses included data from all patients, while efficacy analyses included patients with a baseline and at least 1 postbaseline observation. All results unless otherwise noted were obtained from pre-specified analyses, conducted as described in the statistical analysis plan within the study protocol. The primary outcome of the parent study was an assessment of maintenance of effect of duloxetine $60 \mathrm{mg}$ QD compared with placebo by a comparison of time to relapse among patients who responded to open-label duloxetine treatment. Response was defined as $\geq 50 \%$ decrease in $\mathrm{HAMD}_{17}$ total score from baseline, while remission was defined as a $\mathrm{HAMD}_{17}$ total score $\leq 7$.

In this single-group, open-label study the changes from baseline to endpoint were analyzed with a paired t-test (compared with zero), using the method of last observation carried forward for subjects who withdrew prematurely. The change from baseline to each visit was analyzed using a mixed-effects model repeated measures (MMRM) approach $[26,27]$ which included only visit and investigator as covariates. Response and remission rates are reported as raw values, and do not control for site variation. For laboratory data, the changes from baseline to 
endpoint were analyzed using Wilcoxon signed rank test due to non-normality of the changes.

Within this report, the term "significant" is used to denote statistical significance $(\mathrm{p} \leq .05)$.

\section{Results}

Baseline patient characteristics

A total of 681 patients entered the screening phase of the study, of whom 148 failed to meet entry criteria. Of the 148 patients who did not meet entry criteria, the majority $(76 \%)$ failed to meet the specific protocol entry criteria (described in the selection of patients section). Other reasons for screen failure included patient decision (17\%) and lost to follow-up (4\%).

The remaining 533 patients were enrolled into the 12week open-label acute therapy phase at the 29 study sites (number of patients enrolled at each site: minimum $=2$; maximum $=38$; median $=17$ ). Baseline patient demographics and psychiatric profiles are presented in Table 1. The median exposure to duloxetine was 81 days, and the study yielded data from approximately 92 patient-years of exposure. Concomitant medications used by $\geq 5 \%$ of patients were ibuprofen, acetaminophen, aspirin, naproxen sodium, and multivitamins. During the first 4 weeks of the study, 80 of 529 patients who started acute therapy at a dose of $60 \mathrm{mg}$ QD $(15.1 \%)$ required a temporary dose reduction.

\section{Safety}

Sixteen patients (3.0\%) reported 20 serious adverse events during the 12 week study period. The events occurring in more than 1 patient were suicide attempt $(3 / 533,0.6 \%)$

Table I: Baseline patient demographics and psychiatric profile

\begin{tabular}{lc}
\hline Characteristic & $\begin{array}{c}\text { Duloxetine, 60 mg } \\
\text { QD (N = 533) }\end{array}$ \\
\hline $\begin{array}{l}\text { Gender, } \mathbf{n}(\%) \\
\quad \text { Female }\end{array}$ & $383(71.9)$ \\
Age, mean yrs (SD) & \\
$\quad$ Age range, yrs & $43.4(12.7)$ \\
Weight, mean kg (SD) & $18-76$ \\
Origin, $\mathbf{n}$ (\%) & $82.1(22.3)$ \\
African descent & \\
Caucasian & $34(6.4)$ \\
$\quad$ East/Southeast Asian & $479(89.9)$ \\
Hispanic & $2(0.4)$ \\
Western Asian & $14(2.6)$ \\
Other & $1(0.2)$ \\
Psychiatric profile & $3(0.6)$ \\
I7-Item Hamilton Rating Scale for & \\
Depression total score, mean (SD) & $23.7(3.6)$ \\
Clinical Global Impression of Severity, & \\
mean (SD) & $4.55(0.63)$ \\
\hline
\end{tabular}

and suicidal ideation $(2 / 533,0.4 \%)$. One patient died during the course of the study - death was due to suicide. The completed suicide occurred in a middle-aged male after approximately 2 weeks of treatment with duloxetine, and the principal investigator considered the suicide unrelated to the study drug. Other serious adverse events reported in this study were as follows: unstable angina, anxiety, appendicitis, atrial fibrillation, cerebrovascular disorder, chest pain, confusional state, depression, dizziness, feeling abnormal, necrotizing fascitis, perirectal abscess, skin laceration, and vaginal hemorrhage.

A total of 60/533 patients (11.3\%) discontinued from the study due to adverse events. The majority of discontinuations $(48 / 60)$ occurred at the first three study visits - Week 1 (24), Week 2 (7), and Week 4 (17). Adverse events leading to discontinuation in $\geq 0.5 \%$ of patients were nausea (11/533, 2.1\%), somnolence $(4 / 533,0.8 \%)$, suicide attempt $(3 / 533,0.6 \%)$, and vomiting $(3 / 533,0.6 \%)$. Other reasons for study discontinuation included patient decision $(11.6 \%)$, loss to follow-up $(8.1 \%)$, protocol violation $(5.1 \%)$ and lack of efficacy $(1.9 \%)$. Treatmentemergent adverse events reported by $\geq 5 \%$ of patients are presented in Table 2. The most commonly reported adverse events were nausea, headache, dry mouth, somnolence, insomnia, and dizziness.

A mean baseline-to-endpoint increase in supine HR of 1.7 bpm was observed during the 12 weeks of therapy $(\mathrm{T}=$ $3.9, \mathrm{df}=512, \mathrm{p}<.001)$. Mean changes $(\mathrm{SD})$ in supine systolic and diastolic BP were an increase of $1.4(12.8)$ $\mathrm{mm} \mathrm{Hg}$ and $0.7(9.3) \mathrm{mm} \mathrm{Hg}$, respectively $(\mathrm{T}=2.4, \mathrm{df}=$

Table 2: Treatment-emergent adverse events reported by $\geq 5 \%$ of patients ${ }^{\mathbf{a}}$

\section{n (\%)}

\begin{tabular}{lc}
\hline & $\begin{array}{c}\text { Duloxetine, 60 } \mathbf{~ m g} \\
\text { QD (N = 533) }\end{array}$ \\
\hline Nausea & $191(35.8)$ \\
Headache & $108(20.3)$ \\
Dry mouth & $96(18.0)$ \\
Somnolence & $72(13.5)$ \\
Insomnia & $56(10.5)$ \\
Dizziness & $54(10.1)$ \\
Diarrhea & $53(9.9)$ \\
Constipation & $42(7.9)$ \\
Increased sweating & $37(6.9)$ \\
Anxiety & $33(6.2)$ \\
Decreased appetite & $33(6.2)$ \\
Tremor & $32(6.0)$ \\
Fatigue & $31(5.8)$ \\
Vomiting & $28(5.3)$ \\
\hline
\end{tabular}

a Incidence is defined as the percentage of subjects reporting a first occurrence or worsening of the event during the acute phase of the study. 
$512, \mathrm{p}=.017$, and $\mathrm{T}=1.7, \mathrm{df}=512, \mathrm{p}=.084$, respectively) The incidence of treatment-emergent sustained elevations in blood pressure were: systolic BP - 5/513 (1.0\%); diastolic BP - 4/513 (0.8\%); either systolic or diastolic BP - 8/513 (1.6\%). No patients had PCS low values for blood pressure or heart rate. The incidence of PCS high values were: systolic BP - 1/513 (0.2\%); diastolic BP - 4/513 $(0.8 \%)$; heart rate $-1 / 513(0.2 \%)$.

Patients had a mean decrease in body weight of $-0.1 \mathrm{~kg}$ $[\mathrm{SD}=2.4](\mathrm{T}=-0.7, \mathrm{df}=428, \mathrm{p}=.50)$. One patient $(0.2 \%)$ experienced a PCS weight loss, while two patients $(0.5 \%)$ had a PCS weight gain.

Of the 225 patients having an ECG classified as normal at baseline and having at least 1 post-baseline measurement, $12.4 \%(28 / 225)$ had a treatment-emergent abnormal ECG. No patients $(0 / 402)$ had a treatment-emergent PCS QTcF interval.

Baseline-to-endpoint mean changes on all 4 items of the PGI-SF were negative, indicating an improvement in sexual functioning. When analyzed separately by gender (Table 3), female patients demonstrated significantly greater improvement compared with male patients on item 2 (erection/vaginal lubrication), item 3 (ability to achieve orgasm), and item 4 (overall sexual functioning). The incidence of spontaneously-reported adverse events related to sexual functioning was: erectile dysfunction $2.4 \%$, delayed ejaculation $2.3 \%$, decreased libido $2.3 \%$, anorgasmia $1.7 \%$, abnormal orgasm $1.1 \%$.

Statistically significant mean baseline-to-endpoint changes were observed in some laboratory analytes (e.g. gamma glutamyltransferase: mean change -0.69 U/L (SD
$=23.8)$, Wilcoxon $\mathrm{p}=.002$; alkaline phosphatase: mean change $1.46 \mathrm{U} / \mathrm{L}(\mathrm{SD}=10.9)$, Wilcoxon $\mathrm{p}=.006)$. However, the incidence of treatment-emergent abnormal laboratory values was low. The only analyte with an incidence of abnormal values $\geq 10 \%$ was high creatine phosphokinase $(11.4 \%)$. In the case of liver enzymes, the incidence of alanine transaminase (ALT) and aspartate transaminase (AST) values greater than or equal to $1,3,5,10$, and 20 times the upper limit of normal (ULN) were a priori specified analyses. During acute-phase treatment, 37/377 patients (9.8\%) had ALT values that were greater than $1 \times$, but less than $3 \times$, the ULN. One patient $(0.2 \%)$ had an ALT elevation greater than $3 \times$, but less than $5 \times$, the ULN, while no patients had ALT values that were $\geq 5 \times$ ULN. In the case of AST, $37 / 393$ patients $(9.4 \%)$ had a reading that exceeded $1 \times$, but did not exceed $3 \times$, the ULN. Two patients $(0.5 \%)$ had an AST elevation greater than $3 \times$, but less than $5 \times$, the ULN, and 1 patient $(0.2 \%)$ experienced an AST elevation greater than $5 \times$, but less than $10 \times$, the ULN. In the 28 patients with normal or low bilirubin at baseline who then had treatment-emergent abnormal ALT during acute phase therapy, 1 patient (3.6\%) had a corresponding treatment-emergent abnormal high bilirubin value. The mean baseline-to-endpoint change in total bilirubin did not achieve statistical significance $(0.07$ $\mu \mathrm{mol} / \mathrm{L}(\mathrm{SD}=3.2)$, Wilcoxon $\mathrm{p}=.584)$, while the incidence of abnormal high total bilirubin at anytime was $0.7 \%$. While statistically significant within-group mean changes were observed for some laboratory values, the magnitude of these changes was not considered clinically relevant in light of the small number of treatment-emergent abnormal values. Abnormal values in hepatic enzymes were usually transient and of low magnitude. Increases in ALT/AST values were associated with increases

Table 3: PGI-SF - mean change by gender

\begin{tabular}{|c|c|c|c|c|c|}
\hline & Gender & $\begin{array}{l}\text { Baseline, mean } \\
\text { (SD) }\end{array}$ & $\begin{array}{l}\text { Change, mean } \\
\text { (SD) }\end{array}$ & p-value ${ }^{a}$ & Between-gender p-value \\
\hline \multirow[t]{2}{*}{$\begin{array}{l}\text { Item I Sexual } \\
\text { interest/desire }\end{array}$} & Female $(n=280)$ & $3.57(1.53)$ & $-1.01(1.62)$ & $\begin{array}{c}T=-10.5, \mathrm{df}=279, \mathrm{p}< \\
.001\end{array}$ & $F(I, 370)=0.9, P=.350$ \\
\hline & Male $(n=119)$ & $3.25(1.44)$ & $-0.71(1.67)$ & $T=-4.7, d f=118, p<.001$ & \\
\hline \multirow{2}{*}{$\begin{array}{l}\text { Item } 2 \text { Erection } \\
\text { (male); vaginal } \\
\text { lubrication } \\
\text { (female) }\end{array}$} & Female $(n=270)$ & $2.46(1.56)$ & $-0.53(1.52)$ & $T=-5.8, d f=269, p<.00 I$ & $F(I, 360)=7.6, p=.006$ \\
\hline & Male $(n=119)$ & $2.72(1.46)$ & $-0.29(1.66)$ & $T=-1.9, d f=118, p=.055$ & \\
\hline \multirow{2}{*}{$\begin{array}{l}\text { Item } 3 \text { Ability to } \\
\text { achieve orgasm }\end{array}$} & Female $(n=267)$ & $3.25(1.64)$ & $-0.74(1.74)$ & $T=-7.0, \mathrm{df}=266, \mathrm{p}<.001$ & $F(I, 354)=4.3, p=.038$ \\
\hline & Male $(n=116)$ & $2.55(1.48)$ & $0.14(1.74)$ & $T=0.9, d f=115, p=.396$ & \\
\hline \multirow{2}{*}{$\begin{array}{l}\text { Item } 4 \text { Overall } \\
\text { sexual functioning }\end{array}$} & Female $(n=269)$ & 3.40 (I.59) & $-0.87(1.64)$ & $T=-8.7, d f=268, p<.001$ & $F(I, 359)=4.9, P=.027$ \\
\hline & Male $(n=119)$ & $2.96(1.50)$ & $-0.27(1.7 I)$ & $T=-1.7, d f=118, p=.089$ & \\
\hline
\end{tabular}

a within-stratum $\mathrm{p}$-values from paired t-test.

${ }^{b} \mathrm{p}$-values for gender from ANCOVA with baseline PGI-SF, investigator, and gender in the model.

PGI-SF = Patient Global Impression of Sexual Functioning 
in bilirubin in $1(3.6 \%)$ patient, but the finding was not considered clinically relevant.

\section{Efficacy}

All assessed depression efficacy measures (HAMD ${ }_{17}$, CGIS, PGI-I) showed significant improvement following 12 weeks of duloxetine therapy (Table 4). A visitwise plot of mean change in $\mathrm{HAMD}_{17}$ total score for patients receiving duloxetine (60 mg QD) is presented in Figure 1.

The rate of response at Week 12 was $67.9 \%$ (347/511 patients), while the endpoint remission rate was $52.8 \%$ (270/511 patients; LOCF analyses). Utilizing the entry criteria for the relapse-prevention phase of this study (no longer meeting DSM-IV criteria for MDD; $\mathrm{HAMD}_{17}$ total score $\leq 9$; CGI-S score $\leq 2)$, 280/533 patients (52.5\%) met the entry criteria.

Analyses of mean change in $\mathrm{HAMD}_{17}$ total score revealed no significant treatment-by-strata interactions for age ( $<55$ years vs. $\geq 55$ years), gender, ethnic origin (Caucasian vs. other), baseline HAMD $_{17}$ score ( $<19$ vs. $\geq 19$, or $<25$ vs. $\geq 25$ ), number of previous major depressive episodes (<median vs. $\geq$ median), or treatment history (no previous antidepressants vs. $\geq 1$ previous antidepressant therapy).

Scales assessing the severity of painful physical symptoms (VAS) and somatic symptoms (SQ-SS) showed significant improvement following 12 weeks of duloxetine therapy (Table 5). A visitwise plot of mean changes in the six assessed VAS pain severity questions is shown in Figure 2. Both assessments of quality of life (SDS, QLDS) also demonstrated significant improvement from baseline to endpoint (Table 6).

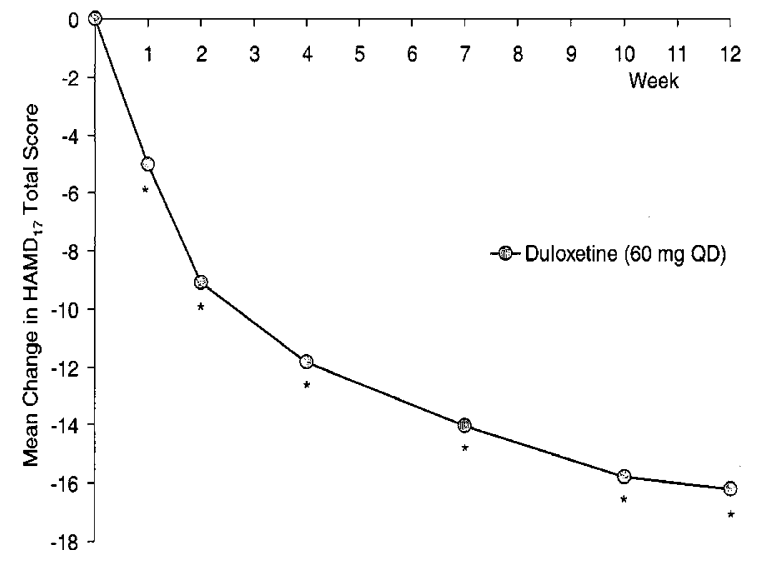

\section{Figure I}

Visitwise plot of mean change in $\mathrm{HAMD}_{17}$ total score for patients receiving duloxetine ( $60 \mathrm{mg} Q D, n=5 \mathrm{I})$. MMRM analysis. ${ }^{*} \mathrm{p}<.00 \mathrm{I}$ from t-test for LS mean change $=0$.

\section{Discussion}

The results of the current investigation are based on the initial 12-week, open-label acute treatment phase of a randomized withdrawal study of duloxetine in the prevention of relapse of MDD. Results of the parent study have been published and show that patients receiving duloxetine $60 \mathrm{mg} / \mathrm{d}$ had significantly longer times to relapse than patients receiving placebo [15]. The current analysis utilized data from an open-label setting to assess the safety and efficacy of a once-daily $60 \mathrm{mg}$ duloxetine dose during acute phase treatment of MDD. Although the study yielded data from a cohort of over 500 patients receiving duloxetine at the target therapeutic dose for up to 12

Table 4: Summary of efficacy measures

\begin{tabular}{|c|c|c|c|}
\hline & Baseline, mean (SD) & Endpoint, mean (SD) & p-value ${ }^{a}$ \\
\hline $\begin{array}{l}\text { Hamilton Rating Scale for Depression total } \\
\text { score }(n=5 \mid I)\end{array}$ & $23.7(3.6)$ & $9.9(7.7)$ & $T=-39.1, d f=510, p<.001$ \\
\hline \multicolumn{4}{|l|}{$\begin{array}{l}\text { Hamilton Rating Scale for Depression } \\
\text { subscales }(n=5 \mid I)\end{array}$} \\
\hline Core & $9.5(1.7)$ & $3.4(3.7)$ & $T=-37.2, \mathrm{df}=510, \mathrm{p}<.001$ \\
\hline Maier & $12.2(2.0)$ & $4.5(4.4)$ & $T=-38.1, d f=510, p<.001$ \\
\hline Anxiety/Somatization & $7.6(1.9)$ & $3.6(2.7)$ & $T=-30.7, d f=510, p<.001$ \\
\hline Retardation & $8.2(1.5)$ & $3.4(3.1)$ & $T=-35.3, \mathrm{df}=510, \mathrm{p}<.001$ \\
\hline Sleep & $3.8(1.7)$ & $1.7(1.8)$ & $T=-23.5, \mathrm{df}=510, \mathrm{p}<.001$ \\
\hline $\begin{array}{l}\text { Clinical Global Impression of Severity }(n= \\
5 \mid 2)\end{array}$ & $4.6(0.6)$ & $2.3(1.3)$ & $T=-36.1, d f=51 I, p<.001$ \\
\hline $\begin{array}{l}\text { Patient Global Impression of Improvement ( } \\
=5 \mathrm{II})\end{array}$ & $\mathrm{N} / \mathrm{A}$ & $2.6(1.4)$ & $\mathrm{N} / \mathrm{A}$ \\
\hline
\end{tabular}

LOCF mean change analysis

a $\mathrm{p}$-values are from paired $\mathrm{t}$-test for mean change from baseline to endpoint $=0$. 
Table 5: Summary of physical symptom efficacy measures

\begin{tabular}{|c|c|c|c|}
\hline & Baseline, mean (SD) & Endpoint, mean (SD) & p-value ${ }^{a}$ \\
\hline \multicolumn{4}{|l|}{ VAS pain severity } \\
\hline Overall $(n=504)$ & $33.8(26.6)$ & $21.3(25.6)$ & $T=-10.5, \mathrm{df}=503 \mathrm{p}<.001$, \\
\hline Headache $(n=504)$ & $27.6(27.8)$ & I5.3 (22.4) & $T=-9.4, d f=503, p<.001$ \\
\hline Back pain $(n=504)$ & $28.7(29.3)$ & $15.8(23.3)$ & $T=-10.7, \mathrm{df}=503, \mathrm{p}<.00 \mathrm{I}$ \\
\hline Shoulder pain $(\mathrm{n}=50 \mathrm{I})$ & $23.1(28.9)$ & $14.1(23.2)$ & $T=-7.7, d f=500, p<.001$ \\
\hline $\begin{array}{l}\text { Interference with daily activities } \\
(\mathrm{n}=50 \mathrm{I})\end{array}$ & $28.2(28.2)$ & $17.3(25.3)$ & $T=-8.8, d f=500, p<.00 I$ \\
\hline $\begin{array}{l}\text { Time in pain while awake }(n= \\
500)\end{array}$ & $38.3(32.2)$ & $23.3(28.6)$ & $T=-10.3, d f=499, p<.00 I$ \\
\hline $\begin{array}{l}\text { Symptom Questionnaire, } \\
\text { Somatic Subscale }(n=492)\end{array}$ & $12.4(5.3)$ & $7.6(5.1)$ & $T=-19.5, d f=49 \mid, p<.001$ \\
\hline $\begin{array}{l}\text { Symptom Questionnaire, } \\
\text { Somatic Subscale pain items } \\
(n=504)\end{array}$ & $4.9(2.4)$ & $3.5(2.6)$ & $T=-11.9, \mathrm{df}=503, \mathrm{p}<.001$ \\
\hline
\end{tabular}

LOCF mean change analysis

${ }^{a} \mathrm{p}$-values are from paired $\mathrm{t}$-test for mean change from baseline to endpoint $=0$

VAS $=$ Visual Analog Scale

weeks, interpretation of results from an open-label study should be approached cautiously. The absence of placebo or active comparator treatment arms limits our ability to draw firm conclusions from the current results, especially with regard to efficacy outcomes. Patients in an openlabel study will exhibit the combined benefits of both drug and placebo responses, and therefore efficacy results such as response and remission rates may be more favorable than those obtained from double-blind, placebo-controlled studies. Furthermore, the statistical significance of treatment outcomes can only be assessed relative to base-

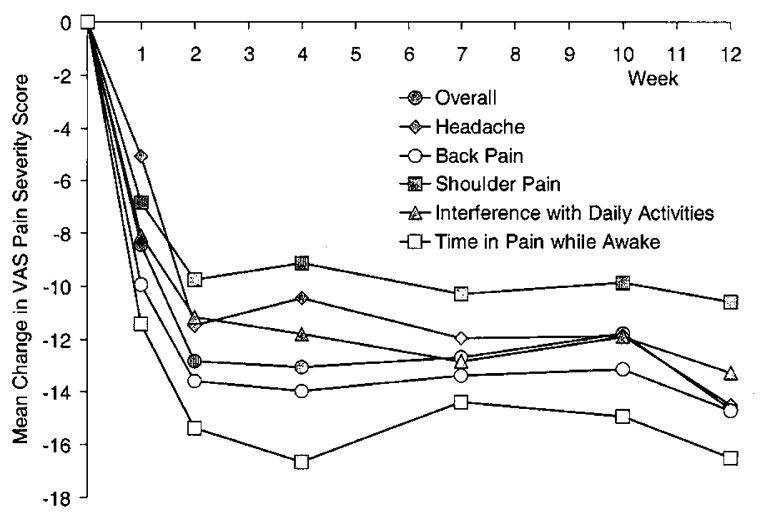

\section{Figure 2}

Visitwise plot of mean change in VAS pain severity scores for patients receiving duloxetine (60 mg QD). MMRM analysis. $P$ $<.00 \mathrm{I}$ for each item at all visits ( $\mathrm{t}$-test for LS mean change $=$ $0)$. line values rather than a comparator group. However, an open-label setting does provide a more realistic approximation of clinical practice when compared with a doubleblind study, and a large study such as this can yield a substantial body of safety and tolerability data. In certain areas, such as rates of discontinuation and the incidence of spontaneously-reported adverse events, results from an open-label study may be especially relevant for practicing clinicians. With these limitations in mind, we discuss in general terms the principal findings from this study. Wherever possible, comparisons with data from previous double-blind, placebo-controlled studies are utilized to provide context for the current results.

The rate of discontinuation due to adverse events in this study $(11.3 \%)$ was similar to that observed in doubleblind, placebo-controlled studies of duloxetine, $60 \mathrm{mg}$ once-daily (13.8\% [9] and $12.5 \%$ [10]) and is also broadly consistent with the reported rates of discontinuation due to adverse events presented in the full prescribing information for other antidepressants (6\% escitalopram [28], 10\% paroxetine controlled release [29], 11\% venlafaxine extended release [30]). Furthermore, the incidence and pattern of treatment-emergent adverse events was also consistent with previously published data. In an analysis of pooled data from placebo-controlled studies of duloxetine (40-120 mg/d), adverse events occurring in $\geq 5 \%$ of duloxetine-treated patients, and at twice the rate for placebo, were nausea, dry mouth, fatigue, dizziness, constipation, somnolence, decreased appetite, and increased sweating [14]. The incidence of treatment-emergent nausea in the present study $(35.8 \%)$ was similar to that reported in 2 placebo-controlled studies of duloxetine $60 \mathrm{mg}$ QD $[9,10]$. Although patients could request a reduction of the duloxetine dose from $60 \mathrm{mg}$ QD to 30 
Table 6: Summary of health outcome measures

\begin{tabular}{|c|c|c|c|}
\hline & Baseline, mean (SD) & Endpoint, mean (SD) & p-value \\
\hline $\begin{array}{l}\text { Quality of Life in Depression } \\
\text { Scale }(n=385)\end{array}$ & $19.0(7.7)$ & $8.2(8.7)$ & $T=-22.6, d f=384, p<.001$ \\
\hline \multicolumn{4}{|l|}{ Sheehan Disability Scale } \\
\hline Total $(n=419)$ & $18.7(5.6)$ & $9.5(7.8)$ & $T=-22.9, \mathrm{df}=4 \mathrm{I} 8, \mathrm{p}<.00 \mathrm{I}$ \\
\hline Work $(n=315)$ & $5.7(2.5)$ & $3.0(2.8)$ & $T=-15.6, d f=314, p<.001$ \\
\hline Social life $(n=419)$ & $6.6(2.3)$ & $3.3(2.9)$ & $T=-22 . I, d f=4 I 8, p<.00 I$ \\
\hline Family life $(n=420)$ & $6.3(2.3)$ & $3.2(2.8)$ & $T=-19.5, \mathrm{df}=419, \mathrm{p}<.001$ \\
\hline
\end{tabular}

LOCF mean change analysis

${ }^{a} \mathrm{p}$-values are from paired t-test for mean change from baseline to endpoint $=0$

mg QD at any point during the first 4 weeks of therapy, $85 \%$ of patients tolerated the starting dose of $60 \mathrm{mg}$ QD without the need for downward titration.

The incidence of spontaneously-reported adverse events related to sexual functioning was relatively low. However, spontaneous reports frequently under-represent the actual incidence of sexual side-effects, and more accurate estimates may be elicited using validated, structured questionnaires. In the present study, the Patient Global Impression of Sexual Function (PGI-SF) questionnaire was utilized to assess treatment-emergent impairment of sexual functioning. Female patients experienced significant within-group mean improvements on all 4 items of the PGI-SF, while male patients experienced improvement on Item 1 (sexual interest/desire). While results from an open-label study should be viewed with a degree of caution, these results suggest that duloxetine does not have a substantial adverse impact upon patient's perception of sexual functioning. By way of comparison, in four doubleblind, placebo- and paroxetine-controlled studies of up to 9 months duration, the Arizona Sexual Experience (ASEX) scale was utilized to compare the incidence of sexual dysfunction in patients receiving duloxetine with the corresponding rates in paroxetine- and placebo-treated patients. Results of an analysis of pooled data from these studies showed that the incidence of acute-phase sexual dysfunction in patients receiving duloxetine (40-120 mg/ d) was significantly lower than that for patients receiving paroxetine (20 mg QD) [31].

Consistent with duloxetine's pharmacological profile as a reuptake inhibitor of $\mathrm{NE}$, a mean increase in heart rate was observed ( $1.7 \mathrm{bpm}$ from baseline to endpoint). The magnitude of this increase is similar to that observed in an analysis of pooled data from acute-phase, placebo-controlled studies of duloxetine ( $1.4 \mathrm{bpm}$ vs. $-0.6 \mathrm{bpm}$ for placebo) [32]. Modest increases in HR have also been observed during treatment of depressed patients with the NE reuptake inhibitor reboxetine (increase in HR of approximately $8 \%$ during 3 weeks of treatment at $4-8 \mathrm{mg} /$ d) [33] and the 5-HT and NE reuptake inhibitor venlafax- ine (increase of $3.8 \mathrm{bpm}$ during 8 weeks of treatment at $225 \mathrm{mg} / \mathrm{d}$ ) [34]. Duloxetine also produced small (less than $2 \mathrm{~mm} \mathrm{Hg}$ ) mean increases in blood pressure - in the case of supine systolic BP the mean change to endpoint (1.4 mm Hg) was statistically but not clinically significant when compared with the baseline value. These mean changes are consistent with those observed in acutephase, placebo controlled studies of duloxetine (40-120 $\mathrm{mg} / \mathrm{d}$ ) [32]. Thus, in an analysis of pooled data, mean change in supine systolic BP was $0.8 \mathrm{~mm} \mathrm{Hg}$ for duloxetine vs. $-1.4 \mathrm{~mm} \mathrm{Hg}$ for placebo $(\mathrm{p}<.001)$, while mean change in supine diastolic BP was $0.9 \mathrm{~mm} \mathrm{Hg}$ for duloxetine vs. $0.4 \mathrm{~mm} \mathrm{Hg}$ for placebo $(\mathrm{p}=.099)$ [32].

In the present study, duloxetine lacked significant effects on the QT interval. None of the 402 patients providing ECG data had a PCS prolongation of corrected QT interval. These data are consistent with results obtained from placebo-controlled studies of duloxetine, which found no evidence for prolongation of QTc intervals in duloxetinetreated patients when compared with those receiving placebo [32].

During the course of this 12 -week study, patients receiving duloxetine had a small $(0.1 \mathrm{~kg})$ decrease in mean body weight. In the absence of a placebo comparator, no definitive conclusions can be drawn concerning the significance of this mean change. However, in an analysis of pooled data from acute-phase, placebo-controlled trials of up to 12 weeks duration, patients receiving duloxetine (40-120 mg/d) exhibited a mean change in weight of $0.46 \mathrm{~kg}$, compared with $0.23 \mathrm{~kg}$ for those receiving placebo $(\mathrm{p}<.001)$ [32]. Furthermore, results from a longterm (52-week) open-label study of duloxetine (80-120 $\mathrm{mg} / \mathrm{d}$ ) demonstrated that mean body weight decreased slightly in the first few weeks of treatment, returned to baseline levels at intermediate visits, and showed an increase of $1.1 \mathrm{~kg}$ at the study endpoint [35].

In a large study with many measures, small clinically insignificant mean changes in laboratory values commonly achieve statistical significance. Thus, in this large 
study, mean changes in some laboratory values were statistically significant, but small in magnitude and of doubtful clinical relevance. However, definitive evidence of non-causality is problematic in the absence of placebo control. In the present study, the incidence of ALT and AST values greater than $1 \times$, but less than $3 \times$ the ULN, were $9.8 \%$ and $9.4 \%$, respectively, while 1 patient $(0.2 \%)$ had an ALT elevation greater than $3 \times$ the ULN. These results are consistent with observations from controlled studies of duloxetine. Within the primary placebo-controlled database (pooled data from 8 studies), the incidence of abnormal (high) values for ALT (duloxetine $9.5 \%$ vs. placebo $7.4 \%$; $\mathrm{p}=.146$ ) and AST (duloxetine $8.1 \%$ vs. placebo $6.0 \% ; \mathrm{p}=.122$ ) did not differ significantly from the placebo rate $[32,36])$, while elevations of ALT greater than $3 \times$ the ULN occurred in $0.9 \%(8 / 930)$ of duloxetinetreated patients compared with $0.3 \%(2 / 652)$ of those receiving placebo [36]. Analyses from another long-term (52-week), open-label clinical study of duloxetine $(\mathrm{N}=$ 2109) showed that duloxetine use was associated with a mild, transient, self-limited rise in ALT and AST, and these changes did not appear to be of clinical significance $[35,36]$.

The efficacy of duloxetine $(40-120 \mathrm{mg} / \mathrm{d})$ in the acute treatment of MDD has been established in a number of acute phase, double-blind, placebo-controlled studies, in addition to a long-term open-label study [9-14,35]. Efficacy results obtained in this study are consistent with those obtained previously at a $60 \mathrm{mg}$ once daily dose $[9,10]$, although double-blind, placebo-controlled studies should be regarded as the primary source of efficacy data, with open-label studies such as this playing a supporting role. The time course of improvement in individual symptom domains is noteworthy. In assessments of depression severity (HAMD ${ }_{17}$, CGI-S) the magnitude of improvement continued to increase at each study visit, while for painful physical symptoms the onset of improvement was rapid and reached a maximum after 2 to 3 weeks of treatment. With regard to duloxetine's effect on overall pain severity improvement, our observations are consistent with experimental data indicating that both 5-HT and NE exert analgesic effects via descending pain pathways [37-39]. The effects on painful symptoms observed in this study are consistent with data from other duloxetine studies demonstrating analgesic effects in depressed patients [40], and the results from the current study are also supportive of those obtained previously from double-blind, placebocontrolled studies which suggest that duloxetine's effect upon painful physical symptoms is, to some extent, independent of its effects upon core emotional symptoms of depression. Thus, in a path analysis of pooled data from 2 placebo-controlled clinical trials, $50 \%$ of duloxetine's total effect on overall pain severity was found to be independent of changes in depressive symptom severity [41].
In the current study, the rate of treatment response ( $\geq 50 \%$ reduction in $\mathrm{HAMD}_{17}$ total score from baseline) was $67.9 \%$, while the remission rate $\left(\mathrm{HAMD}_{17}\right.$ total score $\left.\leq 7\right)$ was $52.8 \%$ (LOCF analysis). In two previously-published placebo-controlled, 9-week studies of duloxetine (60 mg once-daily), estimated probabilities of response (MMRM analysis) were $62 \%$ [9] and 65\% [10] while probabilities of remission were $44 \%$ [9] and $43 \%$ [10]. In other placebo-controlled studies of duloxetine at doses up to 120 $\mathrm{mg} / \mathrm{d}$ probabilities of remission (MMRM) of up to $57 \%$ have been observed [14]. The remission rate in the present study is somewhat higher than that observed in the two placebo-controlled trials involving duloxetine $60 \mathrm{mg}$ once-daily dosing $[9,10]$. As discussed previously, this may be a result of the more favorable treatment outcomes often observed in patients participating in an open-label study. However, other confounding factors also preclude any detailed between-study comparisons, including differing treatment periods (12 weeks in this study vs. 9 weeks in the placebo-controlled studies), somewhat higher baseline severity of depression in the present study (HAMD total score of 23.7 vs. $20-21$ in the placebo-controlled studies), and differing analytical methods (LOCF in the current study vs. MMRM in the placebo-controlled studies).

In summary, both safety and efficacy results from this open-label study are supportive of those obtained from more rigorous double-blind, placebo-controlled trials. The cohort of 533 patients in this study was the largest patient group to receive the recommended therapeutic dose of $60 \mathrm{mg}$ once daily in any duloxetine study to date. Despite the limited utility of efficacy data obtained under open-label conditions, it is hoped that the results described here will provide clinically relevant information for practicing clinicians, especially with regard to the safety and tolerability of duloxetine.

A number of study limitations should be considered when interpreting the present results. As mentioned previously, the principal limitation is the open-label nature of the study and the lack of placebo or active comparator treatment arms. Secondly, the study was of 12 weeks duration and therefore the results are applicable only to acute phase treatment of MDD. Thirdly, patients received a fixed $60 \mathrm{mg}$ dose of duloxetine throughout the study, although the option of a temporary downward titration to $30 \mathrm{mg}$ QD was available at the beginning of the treatment period. Outcomes may have differed if dosing regimens had been optimized on an individual patient basis. Fourthly, patients with serious or unstable medical illnesses were excluded from the study, which limits the generalizability of the current results to a general population of depressed patients. 


\section{Conclusion}

In this open-label study of over 500 patients with a diagnosis of MDD, duloxetine (60 mg QD) was safe and efficacious in the treatment of both emotional and painful physical symptoms of depression. Safety and tolerability results were consistent with those observed previously in double-blind, placebo-controlled studies.

\section{Competing interests}

DP, IG, FW, JW, and MD were employees of Eli Lilly and Company at the time this manuscript was drafted. DP, IG, FW, and MD own Eli Lilly and Company stock. JH has consulted for Eli Lilly and Company and Ortho-McNeil Pharmaceutical, Inc.; and has received research grants from Eli Lilly and Company, Ortho-McNeil Pharmaceutical, Inc., and Forest Laboratories. The article-processing charge for this manuscript is being paid by Eli Lilly and Company.

\section{Authors' contributions}

$\mathrm{DP}, \mathrm{IG}$, and MD conceived of the study, participated in its design and coordination, interpreted the data, and helped to draft the manuscript. FW performed the statistical analysis and interpreted the data. JH participated as a site principal investigator in the study and helped interpret the data. JW interpreted the data and drafted the manuscript. All authors critically reviewed and approved the final manuscript.

\section{Acknowledgements}

This study was designed and sponsored by Eli Lilly and Company. As a result, Eli Lilly and Company collected and analyzed the data, interpreted the data, wrote the manuscript in collaboration with Dr. James Hudson, and jointly decided with Dr. Hudson to submit the manuscript for publication to BMC Psychiatry. The authors wish to thank the study investigators and their patients for participation in this clinical trial. They would also like to thank Stacia Mellinger, BA, for editorial assistance in manuscript preparation.

\section{References}

I. Greden JF: The burden of recurrent depression: causes, consequences, and future prospects. J Clin Psychiatry 200I, 62(Suppl 22):5-9.

2. Wells KB, Stewart A, Hays RD, Burnam MA, Rogers W, Daniels M, Berry S, Greenfield S, Ware J: The functioning and well-being of depressed patients. Results from the Medical Outcomes Study. JAMA 1989, 262:9|4-919.

3. Anderson IM, Tomenson BM: Treatment discontinuation with selective serotonin reuptake inhibitors compared with tricyclic antidepressants: a meta-analysis. BM] 1995, 310:1433-1438

4. Steffens DC, Krishnan KR, Helms MJ: Are SSRIs better than TCAs? Comparison of SSRIs and TCAs: a meta-analysis. Depress Anxiety 1997, 6: 10-18.

5. Anderson IM: Selective serotonin reuptake inhibitors versus tricyclic antidepressants: a meta-analysis of efficacy and tolerability. J Affect Disord 1997, 58: 19-36.

6. Corey-Lisle PK, Nash R, Stang P, Swindle R: Response, partial response, and nonresponse in primary care treatment of depression. Arch Intern Med 2004, 164: I I 97-1204.

7. Bymaster FP, Dreshfield-Ahmad LI, Threlkeld PG, Shaw JL, Thompson L, Nelson DL, Hemrick-Luecke SK, Wong DT: Comparative affinity of duloxetine and venlafaxine for serotonin and norepine- phrine transporters in vitro and in vivo, human serotonin receptor subtypes, and other neuronal receptors. Neuropsychopharmacology 200I, 25:87I-880.

8. Wong DT, Bymaster FP: Dual serotonin and noradrenaline uptake inhibitor class of antidepressants potential for greater efficacy or just hype? Prog Drug Res 2002, 58:169-222.

9. Detke MJ, Lu Y, Goldstein DJ, Hayes JR, Demitrack MA: Duloxetine, $60 \mathrm{mg}$ once daily, for major depressive disorder: a randomized double-blind placebo-controlled trial. J Clin Psychiatry 2002, 63:308-3I5.

10. Detke MJ, Lu Y, Goldstein DJ, McNamara RK, Demitrack MA: Duloxetine $60 \mathrm{mg}$ once daily dosing versus placebo in the acute treatment of major depression. J Psychiatr Res 2002, 36:383.

II. Goldstein DJ, Mallinckrodt C, Lu Y, Demitrack MA: Duloxetine in the treatment of major depressive disorder: a double-blind clinical trial. J Clin Psychiatry 2002, 63:225-23I.

12. Goldstein DJ, Lu Y, Detke MJ, Wiltse C, Mallinckrodt C, Demitrack MA: Duloxetine in the treatment of depression: a doubleblind placebo-controlled comparison with paroxetine. J Clin Psychopharmacol 2004, 24:389-399.

13. Mallinckrodt CH, Goldstein DJ, Detke MJ, Lu Y, Watkin JG, Tran PV: Duloxetine: a new treatment for the emotional and physical symptoms of depression. Prim Care Companion J Clin Psychiatry 2003, 5:19-28.

14. Nemeroff CB, Schatzberg AF, Goldstein DJ, Detke MJ, Mallinckrodt C, Lu Y, Tran PV: Duloxetine for the treatment of major depressive disorder. Psychopharmacol Bull 2002, 36:106-132.

15. Perahia DG, Gilaberte I, Wang F, Wiltse CG, Huckins SA, Clemens JW, Montgomery SA, Montejo AL, Detke MJ: Duloxetine in the prevention of relapse of major depressive disorder. $\mathrm{Br}\rfloor \mathrm{Psy}-$ chiatry 2006, 188:346-353.

16. American Psychiatric Association: Diagnostic and statistical manual of mental disorders 4th edition. Washington, DC: American Psychiatric Association; 1994.

17. Sheehan DV, Lecrubier $Y$, Sheehan $\mathrm{KH}$, Amorim P, Janavs J, Weiller E, Hergueta T, Baker R, Dunbar GC: The Mini-International Neuropsychiatric Interview (M.I.N.I.): the development and validation of a structured diagnostic psychiatric interview for DSM-IV and ICD-10. J Clin Psychiatry 1998, 59(Suppl 20):22-33.

18. Hamilton M: A rating scale for depression. J Neurol Neurosurg Psychiatry 1960, 23:56-62.

19. Guy W: ECDEU assessment manual for psychopharmacology, revised 1976 Rockville, MD: National Institutes of Mental Health; 1976.

20. INC: The sixth report of the joint national committee on prevention, detection, evaluation, and treatment of high blood pressure. 1997. NIH Publication No. 98-4080.

21. Michelson D, Schmidt M, Lee J, Tepner R: Changes in sexual function during acute and six-month fluoxetine therapy: a prospective assessment. J Sex Marital Ther 200I, 27:289-302.

22. DeLoach LJ, Higgins MS, Caplan AB, Stiff JL: The visual analog scale in the immediate postoperative period: intrasubject variability and correlation with a numeric scale. Anesth Analg 1998, 86:102-106.

23. Kellner R: A symptom questionnaire. J Clin Psychiatry 1987, 48:268-274.

24. Hunt SM, McKenna SP: The QLDS: a scale for the measurement of quality of life in depression. Health Policy 1992, 22:307-319.

25. Sheehan DV, Harnett-Sheehan K, Raj BA: The measurement of disability. Int Clin Psychopharmacol 1996, I I (Suppl 3):89-95.

26. Mallinckrodt $\mathrm{CH}$, Sanger TM, Dube S, DeBrota DJ, Molenberghs G Carroll RJ, Potter WZ, Tollefson GD: Assessing and interpreting treatment effects in longitudinal clinical trials with missing data. Biol Psychiatry 2003, 53:754-760.

27. Mallinckrodt CH, Clark SW, Carroll RJ, Molenbergh G: Assessing response profiles from incomplete longitudinal clinical trial data under regulatory considerations. I Biopharm Stat 2003, 13:179-190.

28. Lexapro full prescribing information. . [http://www.Lexa pro.com, revision September 2006, accessed 8JAN2007].

29. Paxil-CR full prescribing information. . [http://www.Paxil.com, revision July 2006, accessed 8JAN2007].

30. Effexor-XR full prescribing information. . [http:// www.Effexor.com, revision August 2006, accessed 8JAN2007].

31. Delgado PL, Brannan SK, Mallinckrodt CH, Tran PV, McNamara RK Wang F, Watkin JG, Detke MJ: Sexual functioning assessed in 4 
double-blind placebo- and paroxetine-controlled trials of duloxetine for major depressive disorder. J Clin Psychiatry 2005, 66:686-692.

32. Hudson JI, Wohlreich MM, Kajdasz DK, Mallinckrodt CH, Watkin JG, Martynov OV: Safety and tolerability of duloxetine in the treatment of major depressive disorder: analysis of pooled data from eight placebo-controlled clinical trials. Hum Psychopharmacol 2005, 20:327-34I.

33. Agelink MW, Ullrich H, Baumann B, Strum S, Majewski T: Effects of reboxetine, a selective norepinephrine reuptake inhibitor, on sympathetic and parasympathetic outflow to the heart: preliminary data. Psychopharmacology (Berl) 2002, 163:15I-156.

34. Bielski RJ, Ventura D, Chang CC: $\mathbf{A}$ double-blind comparison of escitalopram and venlafaxine extended release in the treatment of major depressive disorder. J Clin Psychiatry 2004, 65:1190-1196.

35. Raskin J, Goldstein DJ, Mallinckrodt CH, Ferguson MB: Duloxetine in the long-term treatment of major depressive disorder. J Clin Psychiatry 2003, 64: I 237-1244.

36. Eli Lilly \& Company: Data on file and Cymbalta full prescribing information. . [http://www. Cymbalta.com, revision September 20, 2006]

37. Jones SL: Descending noradrenergic influences on pain. Prog Brain Res |99|, 88:38|-394.

38. Richardson BP: Serotonin and nociception. Ann NY Acad Sci 1990, 600:511-519.

39. Willis WD, Westlund KN: Neuroanatomy of the pain system and of the pathways that modulate pain. J Clin Neurophysiol 1997, 14:2-31.

40. Goldstein DJ, Lu Y, Detke MJ, Hudson J, lyengar S, Demitrack MA: Effects of duloxetine on painful physical symptoms associated with depression. Psychosomatics 2004, 45(I): 17-28.

41. Fava M, Mallinckrodt CH, Detke MJ, Watkin JG, Wohlreich MM: The effect of duloxetine on painful physical symptoms in depressed patients: do improvements in these symptoms result in higher remission rates? J Clin Psychiatry 2004, 65:521-530.

\section{Pre-publication history}

The pre-publication history for this paper can be accessed here:

http://www.biomedcentral.com/1471-244X/7/43/pre

pub

Publish with Bio Med Central and every scientist can read your work free of charge

"BioMed Central will be the most significant development for disseminating the results of biomedical research in our lifetime. "

Sir Paul Nurse, Cancer Research UK

Your research papers will be:

- available free of charge to the entire biomedical community

- peer reviewed and published immediately upon acceptance

- cited in PubMed and archived on PubMed Central

- yours - you keep the copyright 